\title{
Is MTA a Better Pulp Capping Agent than Calcium Hydroxide to Achieve Maturogenesis in Carious, Infected Immature Teeth? A Pilot Study
}

\author{
Mandeep Kaur ${ }^{1}$, Shalini Garg ${ }^{2}$, Abhishek Dhindsa ${ }^{3}$, Rajveer Singh ${ }^{4}$, Sakshi Joshi ${ }^{5}$, Anil Gupta ${ }^{6}$
}

\begin{abstract}
Aim and objective: To compare mineral trioxide aggregate (MTA) and calcium hydroxide as pulp capping agents for the success of coronal pulpotomy of carious, vital immature molars to maintain pulp vitality, and hence allow maturogenesis.

Materials and methods: Thirty immature carious pulpally involved vital molars were included for pulpotomy in a randomized clinical trial. The included molars were allotted into two groups according to the type of pulp capping material used: Group I (control group): calcium hydroxide group (15 molars) and group II (study group): MTA (15 molars) by chit method. The children were recalled for clinical evaluations after 1, 3, 6 , and 9 and 12 months and radiographic examination was done at 6 and 12 months. Maturogenesis was assessed by Nolla's stages of root formation and quantitative analysis to assess maturogenesis was done three dimensionally (width, length and apical closure) by square grid radiographic method.

Results: The mean age of subjects was $9.06 \pm 2.4$ and $9.16 \pm 2.55$ years for the calcium hydroxide group and MTA, respectively $(p=0.918)$. The pulpotomy procedure was significantly successful $(p<0.0005)$ according to all parameters irrespective of the pulp capping agent used. Though MTA performed better in the amount of quantitatively measured dentino-pulpal complex, maturogenesis than calcium hydroxide but the difference was not statistically significant.

Conclusion: Our study concluded that the success of the pulpotomy procedure is not exclusively dependent on the supposed stimulatory effect of a particular type of medicament used but is directly related to the capacity of both dressing and definitive restorative material to provide a biological seal against immediate and long-term microleakage along with the entire restorative interface.

Clinical significance: The coronal seal is the most important clinical factor required to achieve pulpotomy goals in immature permanent carious molars.

Keywords: Immature teeth, Maturogenesis, Mineral trioxide aggregate, Pulpotomy.

World Journal of Dentistry (2021): 10.5005/jp-journals-10015-1837
\end{abstract}

\section{INTRODUCTION}

Dental caries, pulpitis, and further its sequelae are the greatest challenges to the integrity of a developing tooth. Although vital pulp therapy (VPT) in caries-exposed pulps is controversial, ${ }^{1}$ many evidence-based clinical studies support this with recently modified techniques and materials, especially for immature teeth. ${ }^{2}$ Carious exposures in immature teeth may cause irreversible damage to the pulp tissue and leads to arrested root development, which can negatively influence the long-term prognosis of tooth retention. ${ }^{3}$ Therefore, the chief purpose of treating cariously-exposed dental pulp in immature teeth is to maintain pulp vitality and hence to allow continuation of root development and apical closure. This approach is called maturogenesis. ${ }^{4}$ It is a preferred treatment protocol for young immature permanent teeth as it promotes healing by dentino-pulp complex regeneration. Pulpotomy involves the surgical removal of a portion of the affected vital coronal pulp tissue, while the clinician leaves the radicular tissue to allow for normal root development.

One of the most challenging clinical scenario for clinicians is the management of the pulpally involved immature permanent first molar. In all permanent teeth, with or without closed apices, root canal treatment stops the apposition of dentine along the canal walls and pulp chamber leaving the tooth with thin dental walls, and making it prone to fracture. ${ }^{5}$ Pulpotomy is a clinical modality that preserves tooth vitality and maintains pulp functions in cases
${ }^{1}$ Department of Pediatric and Preventive Dentistry, Modern Dental Clinic, Amritsar, Punjab, India

2,5,6 Department of Pediatric and Preventive Dentistry, Faculty of Dental Sciences, SGT University, Gurugram, Haryana, India

${ }^{3}$ Department of Pediatric and Preventive Dentistry, Swami Devi Dayal Dental College, SGT University, Gurugram, Haryana, India

${ }^{4}$ Department of Orthodontics and Dentofacial Orthopedics, Modern Dental Clinic, Amritsar, Punjab, India

Corresponding Author: Shalini Garg, Department of Pediatric and Preventive Dentistry, Faculty of Dental Sciences, SGT University, Gurugram, Haryana, India, Phone: +91 9215668621, e-mail: shaloosandeep@gmail.com

How to cite this article: Kaur M, Garg S, Dhindsa A, et al. Is MTA a Better Pulp Capping Agent than Calcium Hydroxide to Achieve Maturogenesis in Carious, Infected Immature Teeth? A Pilot Study. World J Dent 2021;12(4):285-291.

Source of support: Nil

Conflict of interest: None

of pulp exposure. Young permanent teeth are considered good candidates for many pulp healing procedures because of their greater apical perfusion, which is believed to enhance the pulp ability to react to various insults successfully. ${ }^{6}$ 
Recently, newer dental materials are being developed that are not only bio-restorative but also bio-inductive. With invent of these materials, the emphasis has shifted from mere preservation to regaining vitality and pulp tissue regeneration. One material, which has displayed enormous potential for regeneration is mineral trioxide aggregate (MTA). It is a preferred pulpotomy agent as it initiates dentin bridge formation while simultaneously maintaining normal pulpal histology in radicular part. ${ }^{7}$

Therefore, a pilot study was planned with the purpose to treat cariously exposed dental pulp in immature molars to maintain pulp vitality, arrest, and seal-off the carious infection from progressing to radicular pulp and hence allow continuation of physiological root development and apical closure in all dimensions.

\section{Materials and Methods}

A pilot study was conducted by the Department of Pediatric and Preventive Dentistry for a duration of 1 year. The study protocol, design and methodology were approved by the Ethics Committee of the Institute (Project No: IEC-130).

\section{Selection of Sample}

Initially, 800 children between the age group of 6 years and 12 years were screened for presence of deep carious young immature permanent molars. Fifty-two children were identified as having 1 or 2 symptomatic deeply carious. Furthermore, the parents were provided with the information sheet to educate them along with consent form. The parents were also motivated to report to the department for further radiographic evaluation. Thirtynine children reported and the tooth in question was examined clinically and radiographically according to the following inclusion and exclusion criteria. Thirty children whose parents returned the consent forms were selected and included and divided into two study groups. Group I (control group): calcium hydroxide group 15 molars and group II (study group): MTA 15 molars by chit method of randomization. The children were asked to pick up the chit for allocation into the study group.

In MTA group ( $n=15)$, two children refused to come for regular check-up and hence were excluded from the sample at baseline ( $n=13$ ) and at 3 months follow-up visit one child had dropped from the trial due to loss of follow-up $(n=12)$. However, for calcium hydroxide, no loss or withdrawal was seen at any visit $(n=15)$ (Flowchart 1).

\section{Inclusion and Exclusion Criteria}

Young permanent teeth with incomplete root formation and damage to the coronal pulp but with a presumed healthy radicular pulp, whose crown was fairly intact and restorable and displayed no clinical evidence of extensive pulp degeneration or periapical pathology including spontaneous throbbing pain, tenderness to percussion, swelling, tooth mobility, swelling, or fistulous tract were included.

Flowchart 1: Consort for patient distribution and follow-up

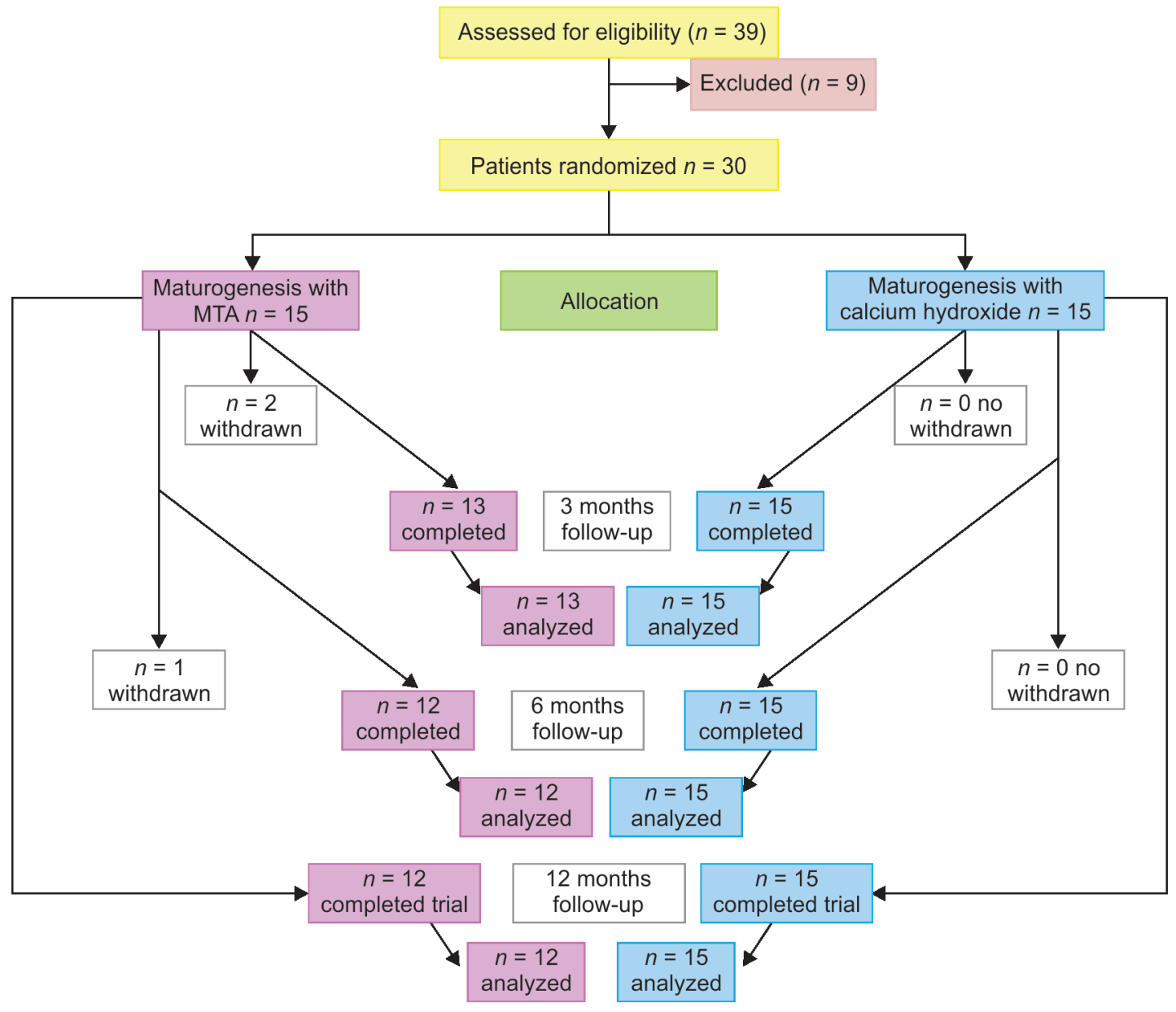


The patients displaying clinical and radiographic features of extensive pulp degeneration or periapical pathology such as evidence of periapical pathosis or inter-radicular bone loss, internal resorption, pulp calcification, ankylosis, or pathologic external root resorption or whose parents did not sign the consent form was excluded from the study.

\section{Assessment and Recording of Preoperative Radiographs}

The intraoral periapical (IOPA) radiographs of each site were digitized using a digital camera (Canon power shot SX1100 IS). The digitized images were then stored in JPEG format, and transferred to adobe photoshop (CS3 extended version) for cropping, and then transferred to Corel draw $X 5$. Wherein the images were then resized to $31 \times 41 \mathrm{~mm}$. Square grid lines of $0.5 \mathrm{~mm}$ were superimposed on the radiographic images (Fig. 1).

\section{Methodology}

In the present trial, the tooth was considered as a unit of study for qualitative analysis, i.e., clinical parameters and radiographic signs of failure of treatment instead of the patient (assessment of Nolla's stages of tooth formation). Furthermore, the unit for quantitative analysis was root (as each treated tooth was a multirooted tooth) to assess maturogenesis in three dimensions (width, length, and apical closure). Thirty molars were finally included in the pilot study. The included molars were allotted into two groups: group I (control group): calcium hydroxide group and group II (study group): MTA.

To avoid any treatment bias, the treatment was carried out by a single operator. Two independent examiners were calibrated and blinded for the groups for clinical and radiographic assessment.

The pulpotomy in the young permanent tooth in both groups was conducted under a rubber dam. Surface anesthesia (lignocaine jelly $2 \%$ cirocaine) application was followed by buccal infiltration of the local anesthetic agent (dentocaine $2 \%$ lignocaine hydrochloride with 1:200,000 adrenaline Pharma healthcare product).

After achieving sufficient anesthesia, a rubber dam was applied and a conventional access opening was carried out with a highspeed bur using copious water spray.

Amputation of the coronal pulp at the cervical level was performed with a sharp spoon excavator (Dentsply, Maillefer) or

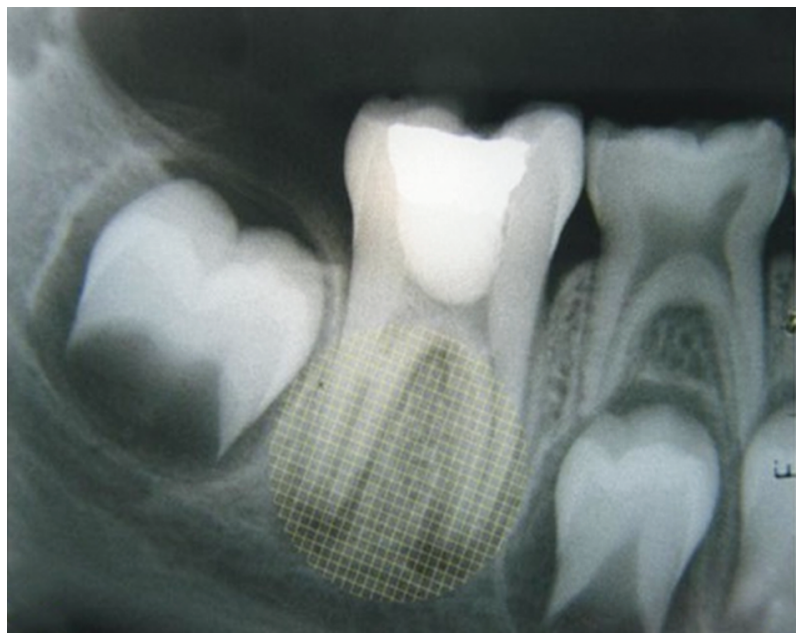

Fig. 1: Superimposition of grid on radiograph for quantitative analysis and appraisal of maturogenesis a large sterile round bur (BR-31, Mani). Strands of pulp and debris were removed coronal to the amputation site and bleeding of the pulp stump was controlled using saline on a cotton pellet applied with gentle pressure.

After control of the bleeding, one of the two materials (calcium hydroxide or MTA) according to the allotted group was applied as per the manufacturer's instructions.

In group I-Calcium hydroxide powder was mixed with saline to achieve a thick consistency and was placed (1-2 $\mathrm{mm}$ ) onto the pulp stump surface.

In group II-The MTA powder was mixed with sterile water according to the manufacturer's directions. The mixture was then placed onto the pulp stump and patted with a moist cotton pellet. A damp cotton pellet was placed over the material and the remaining cavity was filled with fortified zinc oxide-eugenol cement (Temporary filling cement Orafil G) for 24 hours duration.

The final restoration in both groups was done using composite.

\section{Follow-up Visits}

The children were recalled for clinical evaluations after 1, 3, 6, 9, and 12 months. Further for radiographic examination follow-up was done at 6 and 12 months. The success or failure of the treatment was analyzed based on the clinical and radiographic findings (Fig. 2).

\section{Appraisal of Maturogenesis}

Visual analysis of maturogenesis was done by assessing the gain in Nolla's stage of tooth development whereas quantitative analysis was done by placing a grid over the radicular part of the digitized IOPA using the freehand tool of Corel drawX5 for both pre and postoperative radiographs while taking root as a unit of measurement. Any root lengthening, thickening of the root canal, and percentage increase in narrowing of root canal in apical area indicated maturogenesis. Square grid lines of $0.5 \mathrm{~mm}$ were superimposed on the radiographic images. The distance between the two points of each line was measured by using the superimposed square grid lines. Maturogenesis was assessed by subtracting the two measurements; by using the above method for pre- and postoperative radiographs (12 months) (Fig. 1).

\section{Statistical Consideration}

Analyses were conducted using SPSS version 15.0; SPSS Inc., Chicago, IL, USA. Two-sided statistical tests were performed and a $p$ value of $=0.05$ was considered significant .

\section{Results}

In the present study of 27 included teeth, 15 teeth allotted to group I (calcium hydroxide) and 12 teeth in group II (MTA) were subjected to statistical analysis, as three subjects dropped out of study (Flowchart 1). The mean age of subjects was $9.06 \pm 2.4$ and $9.16 \pm 2.55$ years for calcium hydroxide group and MTA, respectively $(p=0.918)$.

According to the clinical criteria, various signs and symptoms, presence or absence of pain, tenderness on percussion, swelling, sinus, mobility, and intact restoration were observed at all follow-up visits. Pulpotomy procedure was highly significantly successful ( $p<$ 0.0005 ) according to all clinical parameters irrespective of the pulp capping agent used. On 12 months follow-up visit, in $\mathrm{Ca}(\mathrm{OH})_{2}$ group one tooth (6.7\%) had pain and two teeth (13.3\%) had tenderness to percussion postoperatively. Swelling, sinus tract presence, and 

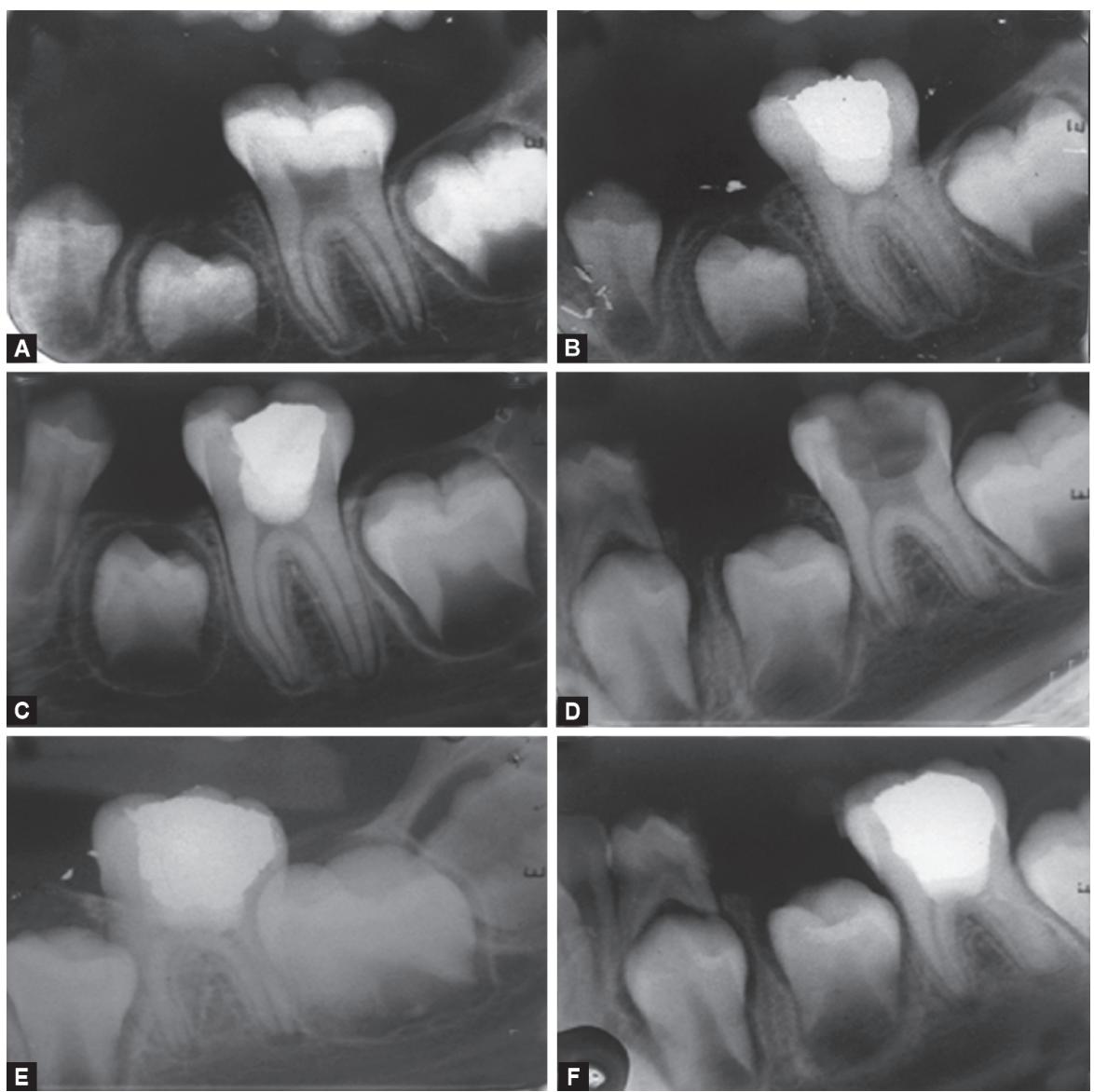

Figs 2A to F: Representative cases showing maturogenesis: calcium hydroxide group [(A) pretreatment; (B) immediate posttreatment; (C) 12 months follow-up] and MTA [(D) pretreatment; (E) immediate posttreatment; (F) 12 months follow-up]

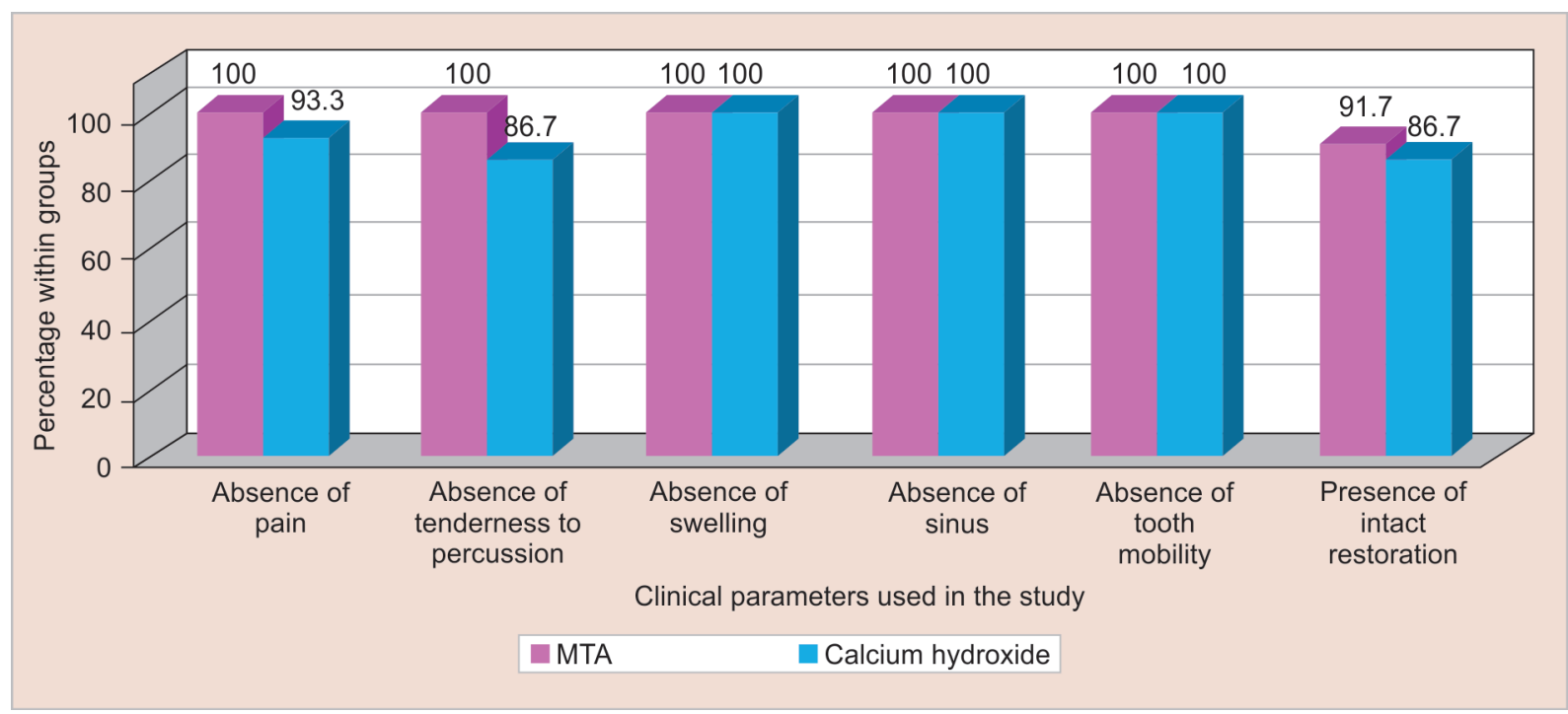

Fig. 3: Clinical criteria assessment for postoperative success

mobility were not observed in any tooth in both the study and control group. Loss of restoration was observed in both groups, one tooth (8.3\%) in MTA group and two teeth (13.3\%) in calcium hydroxide group. Though, MTA performed better than calcium hydroxide according to clinical parameters; however, no statistically significant difference was identified between the two groups using Fisher's exact test ( $p$ value $=1$ ) (Fig. 3).

Radiographic examination of root formation according to Nolla's stages of tooth formation was observed visually by calibrated independence blinded examiner. The root was examined for 
MTA Vital Pulp Therapy in Immature Cariously Involved Teeth

Table 1: Radiographic evaluation comparison between MTA and calcium hydroxide posttreatment

\begin{tabular}{|c|c|c|c|c|c|c|}
\hline Radiographic parameters & Groups & $N$ & Mean & Standard deviation & Mean difference & $p$ value \\
\hline \multirow[t]{2}{*}{$\begin{array}{l}\text { Root lengthening increase in } \\
\text { radiopacity change }\end{array}$} & $\begin{array}{l}\text { Calcium hydroxide } \\
\text { group }\end{array}$ & 31 & 3.0968 & 1.83221 & 0.82323 & 0.058 \\
\hline & MTA group & 25 & 3.9200 & 1.18743 & & \\
\hline \multirow[t]{2}{*}{ Root canal width change } & $\begin{array}{l}\text { Calcium hydroxide } \\
\text { group }\end{array}$ & 31 & 11.3226 & 16.47905 & 0.43742 & .941 \\
\hline & MTA group & 25 & 11.7600 & 26.87514 & & \\
\hline \multirow[t]{2}{*}{$\begin{array}{l}\text { Radiolucency in apical area } \\
\text { change }\end{array}$} & $\begin{array}{l}\text { Calcium hydroxide } \\
\text { group }\end{array}$ & 31 & 1.2258 & 0.71692 & 0.33419 & 0.099 \\
\hline & MTA group & 25 & 1.5600 & 0.76811 & & \\
\hline
\end{tabular}

progress to the next stage of development 12 months after the pulpotomy procedure. Progress from stage 9 (root completed, open apex) to stage 10 (apical foramen closed) was observed in two cases in the calcium hydroxide group as compared to three cases in the MTA group ( $p$ value $=0.628$ ).

Comparing the quantitative development (maturogenesis) achieved root-wise with the use of calcium hydroxide and MTA. Three radiographic criteria were used root lengthening, decrease in root canal width and decrease in apical radiolucency or closure of radiographic apex. For all the three parameters, MTA and calcium hydroxide group did not show statistical difference quantitatively. For root lengthening, a mean increase of $3.09 \pm 1.8$ and $3.9 \pm 1.18$ was observed for calcium hydroxide and MTA groups, respectively, and the mean increase in root canal width was observed to be $11.3 \pm 16.4$ for the calcium hydroxide group and $11.76 \pm 26.87$ for the MTA group. For the third parameter, narrowing of root canal in the apical area, i.e., a mean decrease in the radiolucent apical area of $1.22 \pm 0.71$ and $1.56 \pm 0.76$ for calcium hydroxide and MTA groups, respectively, was observed. However, for all three parameters, no statistically significant difference was observed between both groups (Table 1).

\section{Discussion}

Vital pulp therapy techniques are performed to continue the physiologic dentin deposition, wherein pulpotomy technique involves surgical removal of a portion of affected vital coronal pulp tissue leaving behind radicular tissue in situ to allow normal complete root development known as maturogenesis. The objective, of this type of pulp therapy, is to maintain the integrity, the health of supporting tissues, and vitality of the pulp of a tooth affected by caries, traumatic injuries, or others especially in young permanent teeth with immature roots as the pulp is integral to continue maturogenesis.

In the present study, the age group of 6-12 years was selected as this period of dental chronology corresponds to the eruption, establishment of the occlusal level of incisors, and molars and continuing physiological root development (Nolla's stage 9). All subjects were evaluated for success at 1, 3, 6, 9, and 12 months as per clinical parameters and at 6 and 12 months by radiographic parameters.

Clinical success was $100 \%$ at 1, 3, and 6 months intervals for both MTA and $\mathrm{Ca}(\mathrm{OH})_{2}$ groups. However, at 12 months interval, 100 and $86 \%$ success was observed in MTA and $\mathrm{Ca}(\mathrm{OH})_{2}$ groups, respectively. These results were in accordance with Massler who stated that the most important cause of failure in VPT is bacterial recontamination. ${ }^{6}$ Qudeimat et al. have suggested that the key factor in VPT success is the coronal seal. ${ }^{8}$

The pulpal blood supply is a key factor for the success of pulpotomy. McLachlan et al. stated that markers of inflammation and several proteins of the extracellular matrix are differentially expressed within the pulp tissue, depending on the depth of the carious lesion. ${ }^{9}$ The treatment prognosis is likely to depend on the interplay between infection, inflammation, and regeneration. ${ }^{10}$ Studies by Mente et al. and El-Meligy and Avery have described high clinical success rate when using MTA or biodentine as pulpotomy agents. ${ }^{11,12}$

Nolla's stage of root development, this feature was unique to this study as three teeth $(25 \%)$ in the MTA group had attained Nolla's stage from 9 to 10, and two cases in calcium hydroxide attained Nolla's stage from 9 to $10(13.3 \%)$ posttreatment. Calcium metamorphosis, though not a criterion for success or failure, was a radiographic finding in one tooth treated with $\mathrm{Ca}(\mathrm{OH})_{2}$ and one tooth treated with MTA. In the present study, maturogenesis was measured by three parameters: root length, root width, narrowing of the root canal in the apical area. On comparing the maturogenesis with MTA and $\mathrm{Ca}(\mathrm{OH})_{2}$ pre- and posttreatment using a digital grid method which was done in our study by measuring root growth (root length, root width, and narrowing of the root canal in the apical area). Maturogenesis was observed in all cases of MTA pulpotomy procedure and was highly statistically significant with regards to root lengthening parameter ( $p$ value $=0.001$ ), decrease in root width ( $p$ value $=0.039$ ), and decrease in radiolucency in apical area ( $p$ value $=0.001$ ). Maturogenesis was also observed in all cases of $\mathrm{Ca}(\mathrm{OH})_{2}$ pulpotomy procedure and it was highly statistically significant with regards to root lengthening parameter ( $p$ value $=0.001$ ), decrease in root width ( $p$ value $=0.001$ ), and decrease in radiolucency in apical area ( $p$ value $=0.001$ ). On observing the second parameter, i.e., root lengthening. Mineral trioxide aggregate showed more root lengthening with the mean value of 3.9200 and with a mean difference of 0.82323 . Although, this difference showed better root lengthening with MTA but was not statistically significant. Similar finding are associated with El-Meligy and Avery, ${ }^{12}$ Benoist et al., ${ }^{13}$ and Nosrat et al. ${ }^{14}$ However, the difference between performance of MTA and $\mathrm{Ca}(\mathrm{OH})_{2}$ as pulpotomy agents for maturogenesis was not statistically significant.

The same results were reported by Özgür et al. in a 24 months partial pulpotomy clinical trial, performed with MTA or calcium hydroxide used as the pulp-capping material, provided comparable and favorable outcomes in carious pulp exposures of immature permanent teeth. ${ }^{15}$ Chen et al. in a systematic review and meta- 
analysis concluded that based on the present evidence, similar success rates with MTA were found between the dressing agents like calcium hydroxide, CEM, RPF, and TAP as pulpotomy-dressing agents in the treatment of immature permanent teeth. ${ }^{2}$

We can draw an interference that we can use either of the material but it is the technique, i.e., more important and the impervious coronal seal which makes maturogenesis possible.

Our study concluded that healing of the dental pulp in pulpotomy procedure is not exclusively dependent on the supposed stimulatory effect of a particular type of medicament used but is directly related to the capacity of both dressing and definitive restorative material to provide a biological seal against immediate and long-term microleakage along with the entire restorative interface. ${ }^{16}$ Progress in understanding the molecular and cellular processes during tooth development and how they are mimicked during tissue repair offers the opportunity to assess the biologic strength of VPT. ${ }^{17}$

The result of this study suggests that MTA stimulates new hard tissue formation and promotes pulp better repair. ${ }^{18,19}$ Mineral trioxide aggregate has been able to stimulate hard tissue formation after VPT. ${ }^{20,21}$ It was hypothesized in other studies also that a hard tissue bridge next to MTA may occur because of its excellent sealing properties, ${ }^{22-24}$ biocompatibility, ${ }^{25,26}$ alkalinity, ${ }^{27-29}$ antibacterial properties, $^{30,31}$ or other properties. ${ }^{32,33}$

The noteworthy point is while using MTA is that it needs to be completely set before placing a definitive restoration on the treated tooth. Therefore, it is necessary to schedule two treatment appointments relatively close together: first to perform the pulpotomy and for placement of MTA, second for completing the tooth restoration after MTA was set. ${ }^{29}$ Also, its high cost remains a limiting factor in a country like India.

However, before conclusive inferences regarding better efficacy among two materials can be drawn, a larger sample size with a longer follow-up clinically and radiographically needs to be undertaken at regular intervals to further substantiate the use of either one of the materials in maturogenesis of young permanent teeth.

\section{References}

1. Ward J.Vital pulp therapy in cariously exposed permanent teeth and its limitations. Aust Endod J 2002;28(1):29-37. DOI: 10.1111/j.17474477.2002.tb00364.X.

2. Chen $Y$, Chen $X$, Zhang $Y$, et al. Materials for pulpotomy in immature permanent teeth: a systematic review and meta-analysis. BMC Oral Health 2019;19(1):227. DOI: 10.1186/s12903-019-0917-z.

3. Bjørndal L, Simon S, Tomson PL, et al. Management of deep caries and the exposed pulp. Int Endod J 2019;52(7):949-973. DOI: 10.1111/ iej.13128.

4. Shabahang S, Torabinejad M. Treatment of teeth with open apices using mineral trioxide aggregate. Pract Periodontics Aesthet Dent 2000;12(3):315-320. quiz 322.

5. Camp JH, Barret EJ, Pulver F. Pediatric endodontics: endodontic treatment for the primary and young, permanent dentition. In: Cohen S, Burns RC, ed. Pathways of the pulp. 8th ed., St Louis, MO: Mosby; 2002. pp. 797-844.

6. Massler M. Therapy conducive to healing of the human pulp. Oral Surg, Oral Med, Oral Pathol 1972;34(1):122-130. DOI: 10.1016/00304220(72)90281-2.

7. Schwartz RS, Mauger M, Clement DJ, et al. Mineral trioxide aggregate: a new material for endodontics. J Am Dent Assoc 1999;130(7):967975. DOI: 10.14219/jada.archive.1999.0337.
8. Qudeimat MA, Barrieshi-Nusair KM, Owais Al. Calcium hydroxide vs mineral trioxide aggregates for partial pulpotomy of permanent molars with deep caries. Eur Arch Paediatr Dent 2007;8(2):99-104. DOI: $10.1007 / B F 03262577$.

9. McLachlan JL, Smith AJ, Sloan AJ, et al. Gene expression analysis in cells of the dentine-pulp complex in healthy and carious teeth. Arch Oral Biol 2003;48(4):273-283. DOI: 10.1016/s0003-9969(03) 00003-7.

10. Tabarsi B, Parirokh M, Eghbal MJ, et al. A comparative study of dental pulp response to several pulpotomy agents. Int Endod J 2010;43(7):565-571. DOI: 10.1111/j.1365-2591.2010.01711.x.

11. Mente J, Geletneky B, Ohle M, et al. Mineral trioxide aggregate or calcium hydroxide direct pulp capping: an analysis of the clinical treatment outcome. J Endod 2010;36(5):806-813. DOI: 10.1016/j. joen.2010.02.024.

12. El-Meligy OA, Avery DR. Comparison of mineral trioxide aggregate and calcium hydroxide as pulpotomy agents in young permanent teeth (apexogenesis). Pediatr Dent 2006;28(5):399-404.

13. Leye Benoist F, Gaye Ndiaye F, Kane AW, et al. Evaluation of mineral trioxide aggregate (MTA) versus calcium hydroxide cement (Dycal $\left({ }^{(}\right)$) in the formation of a dentine bridge: a randomised controlled trial. Int Dent J 2012;62(1):33-39. DOI: 10.1111/j.1875-595X.2011.00084.x.

14. Nosrat A, Seifi A, Asgary S. Pulpotomy in caries-exposed immature permanent molars using calcium-enriched mixture cement or mineral trioxide aggregate: a randomized clinical trial. Int J Paediatr Dent 2013;23(1):56-63. DOI: 10.1111/j.1365-263X.2012.01224.x.

15. Özgür B, Uysal S, Güngör HC. Partial pulpotomy in immature permanent molars after carious exposures using different hemorrhage control and capping materials. Pediatr Dent 2017;39(5):364-370.

16. Moretti AB, Sakai VT, Oliveira TM, et al. The effectiveness of mineral trioxide aggregate, calcium hydroxide and formocresol for pulpotomies in primary teeth. Int Endod J 2008;41(7):547-555. DOI: 10.1111/j.1365-2591.2008.01377.x.

17. Fuks AB. Current concepts in vital primary pulp therapy. Eur J Paediatr Dent 2002;3(3):115-120.

18. Ford TR, Torabinejad M, McKendry DJ, et al. Use of mineral trioxide aggregate for repair of furcal perforations. Oral Surg Oral Med Oral Pathol Oral Radiol Endod 1995;79(6):756-763. DOI: 10.1016/s10792104(05)80313-0.

19. Aqrabawi J. Sealing ability of amalgam, super EBA cement, and MTA when used as retrograde filling materials. Br Dent J 2000;188(5):266268. DOI: 10.1038/sj.bdj.4800450.

20. Wu MK, Kontakiotis EG, Wesselink PR. Long-term seal provided by some root-end filling materials. J Endod 1998;24(8):557-560. DOI: 10.1016/S0099-2399(98)80077-0.

21. Arruda RA, Cunha RS, Miguita KB, et al. Sealing ability of mineral trioxide aggregate (MTA) combined with distilled water, chlorhexidine, and doxycycline. J Oral Sci 2012;54(3):233-239. DOI: 10.2334/josnusd.54.233.

22. Torabinejad M, Watson TF, Pitt Ford TR. Sealing ability of a mineral trioxide aggregate when used as a root end filling material. J Endod 1993;19(12):591-595. DOI: 10.1016/S0099-2399(06)80271-2.

23. Torabinejad M, Hong CU, Lee SJ, et al. Investigation of mineral trioxide aggregate for root-end filling in dogs. J Endod 1995;21(12):603-608. DOI: 10.1016/S0099-2399(06)81112-X.

24. Torabinejad M, Hong CU, McDonald F, et al. Physical and chemical properties of a new root-end filling material. J Endod 1995;21(7):349353. DOI: 10.1016/S0099-2399(06)80967-2.

25. Torabinejad M, Rastegar AF, Kettering JD, et al. Bacterial leakage of mineral trioxide aggregate as a root-end filling material. J Endod 1995;21(3):109-112. DOI: 10.1016/s0099-2399(06)80433-4.

26. Faraco IM. Jr, Holland R. Response of the pulp of dogs to capping with mineral trioxide aggregate or a calcium hydroxide cement. Dent Traumatol 2001;17(4):163-166. DOI: 10.1034/j.16009657.2001.170405.x.

27. Aeinehchi $M$, Eslami $B$, Ghanbariha $M$, et al. Mineral trioxide aggregate (MTA) and calcium hydroxide as pulp-capping agents in human 
teeth: a preliminary report. Int Endod J 2003;36(3):225-231. DOI: 10.1046/j.1365-2591.2003.00652.x.

28. Holland R, de Souza V, Murata SS, et al. Healing process of dog dental pulp after pulpotomy and pulp covering with mineral trioxide aggregate or Portland cement. Braz Dent J 2001;12(2): 109-113.

29. Dominguez MS, Witherspoon DE, Gutmann JL, et al. Histological and scanning electron microscopy assessment of various vital pulp-therapy materials. J Endod 2003;29(5):324-333. DOI: 10.1097/00004770-200305000-00003.

30. Chacko V, Kurikose S. Human pulpal response to mineral trioxide aggregate (MTA): a histologic study. J Clin Pediatr
Dent 2006;30(3):203-209. DOI: 10.17796/jcpd.30.3 38 h13g5p84651652.

31. Al-Hezaimi K, Al-Shalan TA, Naghshbandi J, et al. Antibacterial effect of two mineral trioxide aggregate (MTA) preparations against enterococcus faecalis and Streptococcus sanguis in vitro. J Endod 2006;32(11):1053-1056. DOI: 10.1016/j.joen.2006.06.004.

32. Asgary $S$, Shahabi $S$, Jafarzadeh $T$, et al. The properties of a new endodontic material. J Endod 2008;34(8):990-993. DOI: 10.1016/j. joen.2008.05.006.

33. Sarkar NK, Caicedo R, Ritwik P, et al. Physicochemical basis of the biologic properties of mineral trioxide aggregate. J Endod 2005;31(2):97-100. DOI: 10.1097/01.don.0000133155.04468.41. 